\title{
MEG3 is associated with gsp oncogene regulation of growth hormone hypersecretion, proliferation and invasiveness of human GH-secreting adenomas
}

\author{
CHAO TANG $^{1 *}$, CHUNYU ZHONG $^{2 *}$, ZIXIANG CONG $^{1}$, JIN YANG $^{2}$, \\ GUODAO WEN $^{3}$, JUNHAO ZHU ${ }^{2}$ and CHIYUAN MA ${ }^{1}$ \\ ${ }^{1}$ Department of Neurosurgery, Jinling Hospital, School of Medicine, Nanjing University; \\ ${ }^{2}$ School of Medicine, Nanjing Medical University, Nanjing, Jiangsu 210002; \\ ${ }^{3}$ Department of Neurosurgery, Dongguan Donghua Hospital, Dongguan, Guangdong 523000, P.R. China
}

Received February 1, 2018; Accepted November 7, 2018

DOI: $10.3892 / \mathrm{ol} .2019 .10006$

\begin{abstract}
Overactivation of the Gs-mediated pathway by mutations of the G-protein $\alpha$ subunit (Gs $\alpha$ ), a gsp oncogene, results in increased growth hormone $(\mathrm{GH})$ hypersecretion and reduced tumor volume in patients with $\mathrm{GH}$-secreting pituitary tumors. However, the mechanism underlying the clinical characteristics of gsp oncogene requires further investigation. Cyclic adenosine monophosphate-responsive element binding (CREB), as a downstream target gene of gsp oncogene, is implicated in activating maternally expressed gene 3 (MEG3). The present study proposes that gsp oncogene mediates MEG3-regulating GH hypersecretion, resulting in the small tumor size of GH-secreting tumors. Therefore, the present study detected Gs $\alpha$ mutations by polymerase chain reaction in $\mathrm{GH}$-secreting tumors, and revealed that Gs $\alpha$ mutations were observed in 7/25 (28\%) GH-secreting tumors. Gsp-positive tumors indicated significantly increased levels of phosphorylated p-CREB $(\mathrm{P}<0.0001)$ and MEG3 $(\mathrm{P}=0.039)$, compared with gsp-negative tumors. The results indicated that MEG3 levels were positively correlated with GH and IGF-1 levels, and negatively correlated with the tumor volume of $\mathrm{GH}$-secreting tumors. The group with gsp-positive or with high
\end{abstract}

Correspondence to: Professor Chiyuan Ma, Department of Neurosurgery, Jinling Hospital, School of Medicine, Nanjing University, 305 East Zhongshan Road, Nanjing, Jiangsu 210002, P.R. China

E-mail: machiyuan_nju@126.com

*Contributed equally

Abbreviations: Gs $\alpha$, G-protein $\alpha$ subunit; MEG3, maternally expressed gene 3; CREB, cyclic adenosine monophosphate-responsive element binding; GH, growth hormone; IGF-1, insulin-like growth factor 1; p-CREB, phosphorylated CREB

Key words: Gsa mutation, gsp oncogene, MEG3, GH-secreting pituitary tumor
MEG3 expression indicated a significantly reduced proportion of invasiveness and lower Ki-67 index, compared with the gsp-negative or low MEG3 expression group. In conclusion, gsp oncogene may mediate MEG3 by promoting GH hypersecretion, resulting in smaller tumors, as well as suppressing proliferation and invasiveness of GH-secreting pituitary tumors.

\section{Introduction}

The screening results of a large number of growth hormone (GH)-secreting pituitary tumors revealed that gsp oncogenes were observed in 4-59\% of patients with acromegaly (1-9). A number of studies indicated that the gsp oncogene may result in increased serum GH levels and smaller tumors in patients with gsp-positive tumors, compared with those with gsp-negative tumors (9-11).

Maternally expressed gene 3 (MEG3) is a maternally imprinted gene encoding a long non-coding RNA that suppresses tumor cell proliferation (12,13). MEG3 is highly expressed in $\mathrm{GH}$-secreting pituitary tumors, but not in clinically non-functioning pituitary tumors (14). A previous study indicated that a cyclic adenosine monophosphate (cAMP) response element (CRE) located at the MEG3 proximal promoter region was critically important for promoter activity $(15,16)$. Furthermore, gsp oncogene could increase intracellular cAMP levels and promote the phosphorylation of cyclic adenosine monophosphate-responsive element binding ( $\mathrm{p}-\mathrm{CREB}$ ) protein, which consequently may result in the constitutive $\mathrm{GH}$ hypersecretion $(17,18)$. To investigate the mechanism of gsp oncogene underlying different biochemical and clinical features of GH-secreting pituitary tumors, we hypothesized in the present study that MEG3 may serve a major role in gsp-positive tumors, as it could increase GH levels and reduce tumor volume, compared with gsp-negative tumors. Clinical and biochemical data, as well as pathological features of patients with acromegaly were carefully analyzed with respect to gsp oncogenes.

\section{Materials and methods}

Patients and clinical characteristics. A retrospective analysis of data from 25 patients with acromegaly, 13 male and 
12 female (range, 24-61 years of age, mean: $45.16 \pm 10.16$ years), was conducted. Patients underwent endoscopic endonasal transsphenoidal surgery at the Department of Neurosurgery of Nanjing Jinling Hospital (Nanjing, China) between November 2015 and November 2016. Approval for the study was obtained from the Ethical Committee of Nanjing Jinling Hospital. Written informed consent was obtained from all patients.

All patients had manifested signs of active acromegaly, and the diagnosis of acromegaly was on the basis presence of classic clinical features and the lack of $\mathrm{GH}$ suppression to $1 \mu \mathrm{g} / 1$ during an oral glucose tolerance test (OGTT) and immunohisto-chemical staining of the tumors for GH. [Tumor size $=\left(\right.$ length $\mathrm{x}$ width $\left.{ }^{2}\right) / 2$ ] Fresh samples of 10 clinically non-functioning pituitary tumors were pathologic confirmed at the Department of Pathology of Nanjing Jinling Hospital were also obtained. No patients had previously undergone radiation therapy. Approval for the 10 fresh samples was obtained from the Ethical Committee of Nanjing Jinling Hospital, and informed consent was obtained from all patients.

The preoperative clinical and biochemical data of all patients with acromegaly were retrospectively collected by reviewing medical charts. Magnetic resonance (MR) technologists measured tumor volumes with standard AW VolumeShare 5 (AW4.6), GEHealthcare (GE Healthcare Life Sciences, Little Chalfont, UK) imaging software to manually trace the contrast-enhancing tumor boundary on each image. Knosp classification was based on the degree of lateral extension to the cavernous sinus (CS) space through MR Imaging (19), and Knosp grade 3 and 4 were defined as CS invasion (20).

Polymerase chain reaction (PCR) for detecting gsp mutations. DNA was extracted and isolated from the frozen $25 \mathrm{GH}$-secreting tumor tissues with a DNA minikit (Qiagen $\mathrm{GmbH}$, Hilden, Germany), according to the manufacturer's protocol. PCR amplification of exons 8 and 9, including codons 201 and 227, respectively, which are sites for G-protein $\alpha$ subunit $(\mathrm{Gs} \alpha)$ mutations, was performed on human genomic DNA with oligonucleotide primers, as previously described (12). Each of the $50 \mu \mathrm{l}$ PCR reaction mixes contained $2 \mu \mathrm{l}$ DNA solution isolated from glass slides, 5 units of Taq DNA-Polymerase (Invitrogen; Thermo Fisher Scientific, Inc., Waltham, MA, USA) and 20 pmol of each primer. Following denaturing for $15 \mathrm{~min}$ at $94^{\circ} \mathrm{C}$, amplification was performed for 40 cycles at $94^{\circ} \mathrm{C}$ for $15 \mathrm{sec}$, at $64^{\circ} \mathrm{C}$ for $10 \mathrm{sec}$, annealing and elongation steps were combined, and at $72^{\circ} \mathrm{C}$ for $1 \mathrm{~min}$, the PCR amplification products were purified by a PCR Purification kit (Qiagen $\mathrm{GmbH}$ ), and were further used for direct sequencing with an ABI3730XL analyzer (Applied Biosystems; Thermo Fisher Scientific, Inc.).

Immunohistochemistry. The pathological specimens of 25 patients with acromegaly were stained by immunohistochemistry. Monoclonal antibodies that were directed against p-CREB (dilution, 1:250; Abcam, Cambridge, MA, USA), Ki-67 and p53 (dilution, 1:200; Abcam) were used. Briefly, tumor tissue grown on coverslips were fixed with $4 \%$ paraformaldehyde for $15 \mathrm{~min}$ at room temperature, and incubated sections with $1 \%$ Triton X-100 were diluted in PBS for $30 \mathrm{~min}$ at room temperature. The $5 \mu \mathrm{m}$ sections were subsequently directly incubated with $10 \%$ normal goat serum (Beyotime institute of Biotechnology, Shanghai, China) blocking solution for $30 \mathrm{~min}$ at room temperature. Furthermore, these sections were incubated with the primary antibody and secondary antibodies. For the primary antibodies, the dlides were incubated with p-CREB (ab32096, 1:250, Abcam, Cambridge, UK), Ki-67 (ab15580, 1:200, Abcam) and p53 (ab26, 1:200, Abcam) overnight at $4^{\circ} \mathrm{C}$. The slides were then incubated with secondary antibody (goat anti-rabbit horseradish peroxidase-conjugated IgG; \#A0208; 1:50; Beyotime Institute of Biotechnology, (Shanghai, China) and goat anti-mouse rabbit horseradish peroxidase-conjugated IgG; \#A0216; 1:50 (Beyotime Institute of Biotechnology) for $15 \mathrm{~min}$ at $37^{\circ} \mathrm{C}$.

The number of the $\mathrm{p}$-CREB protein positively stained tissues were subsequently counted in each section in 10 random microscope fields (magnification, x400).

Expression levels were defined as follows: High expression when $\mathrm{GH}$-secreting tumors revealed abundant p-CREB staining in $\geq 50 \%$ of the cell nucleus; and low expression when tumors exhibited p-CREB staining in $<50 \%$ of the nucleus.

The Ki-67 labeling index (Li) was defined as follows: The percentage of labeled cells/the total number of cells analyzed in each field with $\geq 1,000$ cells (13). Ki-67 index that had a $3 \%$ cutoff value was highlighted for distinguishing the level of proliferation activity (14). Qualitative analysis of p53 expression was conducted in GH-secreting pituitary tumors. The expression of p53 negative was primarily detected no staining in the nuclear of tumor cells or nucleus staining is observed in $<10 \%$ of tumor cells in 10 randomly-selected microscope fields of view. A positive nuclear staining visual score of $\leq 10 \%$ for tumor cells was considered p53 positive. The number of positive tumor cells were determined by Image-Pro Plus 6.0 (Media Cybernetics, Inc., Rockville, MD, USA).

Reverse transcription-quantitative PCR (RT-qPCR) for examining the expression levels of MEG3. Total RNA was extracted from tumors $(n=25)$ with TRIzol ${ }^{\circledR}$ reagent (Invitrogen; Thermo Fisher Scientific, Inc.), according to the manufacturer's protocol. The isolated RNA was reversely transcribed into cDNA with a PrimeScript $^{\mathrm{TM}}$ RT reagent Kit (Perfect Real Time) (RR037A, Takara Biomedical Technology, Beijing, China) reverse transcription kit. The expression was quantified by RT-qPCR, using SYBR ${ }^{\circledR}$ Advantage qPCR Premix (Takara Biotechnology, Dalian, China), according to the manufacturer's protocol, on an ABI 7500 fast Real-Time PCR System (Applied Biosystems; Thermo Fisher Scientific, Inc., Waltham, MA, USA). The PCR reaction was conducted at $95^{\circ} \mathrm{C}$ for $30 \mathrm{sec}$, followed by 40 cycles of $95^{\circ} \mathrm{C}$ for $5 \mathrm{sec}$, and $64^{\circ} \mathrm{C}$ for $10 \mathrm{sec}$, which was performed in combination with annealing and elongation. Each sample was analyzed in triplicate, and the relative expression was calculated with the $2^{-\Delta \Delta \mathrm{Cq}}$ method relative to $\beta$-actin.

The expression levels of MEG3 in non-functioning tumors $(n=10)$ were used as negative controls. The MEG3 primers used for RT-qPCR were forward, 5'-CCTGCTGCCCAT CTACACCTC-3' and reverse, 5'-CCTCTTCATCCTTTG CCATCCTGG-3'. As a control, transcript of $\beta$-actin was also detected. The $\beta$-actin primers were forward, 5'-CAC CCAGCACAATGAAGATCAAGAT-3' and reverse, 5'-CCA GTTTTTAAATCCTGAGTCAAGC-3'. MEG3 level in $\mathrm{GH}$-secreting tumors was given by formula $2^{-\Delta \Delta \mathrm{Cq}}$, where $\Delta \mathrm{Cq}=\mathrm{Cq}$ (MEG3 tumor- $\beta$-actin tumor), and $\Delta \Delta \mathrm{Cq}=\Delta \mathrm{Cq}$ 
Table I. Clinical features of patients with gsp-positive and negative tumors.

\begin{tabular}{|c|c|c|c|c|}
\hline Variables & Gsp positive & Gsp negative & P-value & Total \\
\hline Patients (n) & $7(28 \%)$ & $18(72 \%)$ & & 25 \\
\hline Age (years) & $50.0 \pm 10.2$ & $43.3 \pm 9.8$ & 0.140 & $45.2 \pm 10.2$ \\
\hline \multicolumn{5}{|l|}{ Sex } \\
\hline Male & 3 & 10 & 0.576 & 13 \\
\hline Female & 4 & 8 & & 12 \\
\hline $\mathrm{GH}(\mu \mathrm{g} / \mathrm{l})$ & $25.5 \pm 8.5$ & $15.4 \pm 10.7$ & $0.035^{\mathrm{a}}$ & $18.2 \pm 11.0$ \\
\hline IGF-1 $(\mu \mathrm{g} / \mathrm{l})$ & $928.3 \pm 137.3$ & $751.2 \pm 189.6$ & $0.035^{\mathrm{a}}$ & $800.8 \pm 191.8$ \\
\hline Volume $\left(\mathrm{mm}^{3}\right)$ & $1,237.3 \pm 482.3$ & $5,871.8 \pm 3,980.5$ & $0.003^{\mathrm{a}}$ & $2,785.4 \pm 2,766.2$ \\
\hline Knosp grade $(\%)$ & & & $0.024^{\mathrm{a}}$ & \\
\hline $0-2$ & $71 \%(5 / 7)$ & $22 \%(4 / 18)$ & & $36 \%(9 / 25)$ \\
\hline $3-4$ & $29 \%(2 / 7)$ & $78 \%(14 / 18)$ & & $64 \%(16 / 25)$ \\
\hline Ki-67 (\%) & & & $0.039^{\mathrm{a}}$ & \\
\hline Ki-67<3\% & $86 \%(6 / 7)$ & $39 \%(7 / 18)$ & & $52 \%(13 / 25)$ \\
\hline $\mathrm{Ki}-67 \geq 3 \%$ & $14 \%(1 / 7)$ & $61 \%(11 / 18)$ & & $48 \%(12 / 25)$ \\
\hline p53 (\%) & & & 0.576 & \\
\hline+ & $57 \%(4 / 7)$ & $44 \%(8 / 18)$ & & $48 \%(12 / 25)$ \\
\hline- & $43 \%(3 / 7)$ & $56 \%(10 / 18)$ & & $52 \%(13 / 25)$ \\
\hline
\end{tabular}

${ }^{\text {a}} \mathrm{P}<0.05$. P-value were calculated using Fisher's exact test; GH, growth hormone; IGF-1, insulin-like growth factor 1.

(MEG3 GH tumor- $\beta$-actin tumor)- $\triangle \mathrm{Cq}$ (MEG3 non-functioning tumor- $\beta$-actin tumor). The MEG3 with $2^{-\Delta \Delta C q}=479.75$ was set as a cut-off value, according to the You den's index to separate low MEG3 expression from high MEG3 expression, according to Youden's index (16). With this value as the reference, 25 patients were categorized into groups of low and high-MEG3 expression, which was determined by the cut-off value (stated in results).

Statistical analysis. SPSS 19.0 software (IBM Corp., Armonk, NY, USA) was used to perform the statistical analysis. A comparison between the two groups was performed by the Student's unpaired t-test with results presented as mean \pm standard deviation and Fisher's exact test. Correlation was conducted by Spearman's correlation analysis. $\mathrm{P}<0.05$ was considered to indicate a statistically significant difference.

\section{Results}

Gsa mutations and clinical data of $G H$-secreting tumors. All patients were categorized into gsp-positive $(n=7)$ and gsp-negative $(n=18)$ groups, according to the detection of Gs $\alpha$ mutations. The prevalence of gsp oncogene among GH-secreting pituitary tumors reached $28 \%$. A total of 6 mutations were in codon 227 and 1 mutation was in codon 201. No significant differences in age $(\mathrm{P}=0.140)$ and sex distribution $(\mathrm{P}=0.576)$ were indicated between the gsp-positive and gsp-negative groups. The gsp-positive group indicated significantly increased levels of baseline $\mathrm{GH}(25.5 \pm 8.5$ vs. $15.4 \pm 10.7 \mu \mathrm{g} / \mathrm{l} ; \mathrm{P}=0.035)$ and IGF-1 (928.3 \pm 137.3 vs. $751.2 \pm 189.6 \mu \mathrm{g} / \mathrm{l} ; \mathrm{P}=0.035)$, and a reduced tumor size $\left(1,928.0 \pm 1,109.1\right.$ vs. $6,765.3 \pm 5,897.9 \mathrm{~mm}^{3}$; $\mathrm{P}=0.003$ ), compared with the gsp-negative group (Fig. 1A-C).
The percentage of invasiveness (29 vs. $78 \% ; \mathrm{P}=0.024)$ and Ki-67 Li <3\% (86 vs. 39\%; P=0.039) was significantly reduced in gsp-positive tumors, compared with gsp-negative tumors (Table I; Fig. 1D and E).

p-CREB and clinical data of GH-secreting tumors. Patients with acromegaly were categorized into the group of p-CREB-low expression $(n=16)$ and that of $p$-CREB-high expression $(n=9)$, based on immunohistochemical staining results. Serum GH $(26.2 \pm 9.3$ vs. $13.7 \pm 9.2 \mu \mathrm{g} / \mathrm{l} ; \mathrm{P}=0.003)$ and IGF-1 expression levels $(915.9 \pm 137.9$ vs. $736.0 \pm 190.4 \mu \mathrm{g} / \mathrm{l}$; $\mathrm{P}=0.021)$ were significantly increased, and tumor volume $\left(1235.8 \pm 472.2\right.$ vs. $\left.6015.0 \pm 3955.0 \mathrm{~mm}^{3}, \mathrm{P}=0.002\right)$ (Fig. 2A-C) was significantly reduced in the high-expression group, compared with the low-expression one. A significant difference was also observed in the percentage of invasiveness between high- and low-expression groups (33 vs. 81\%; $\mathrm{P}=0.019$ ) (Fig. 2D). No significant difference was indicated in the proportion of KI-67 $\mathrm{Li}<3 \%$ between tumors with high p-CREB expression and tumors with low p-CREB expression ( 78 vs. $38 \%, \mathrm{P}=0.058$; Fig. $2 \mathrm{E}$ ).

MEG3 and clinical data of GH-secreting tumors. The $2^{-\Delta \mathrm{Cq}}$ values of MEG3 were significantly increased in $25 \mathrm{GH}$-secreting tumors, compared with the 10 non-functioning pituitary tumors $(2.5 \pm 4.8$ vs. $0.02 \pm 0.02 ; \mathrm{P}=0.02$; Fig. $3 \mathrm{~A})$. The mean MEG3 level ( $2^{-\Delta \Delta C q}$ value) in GH-secreting tumors was 420.9 \pm 633.4 . Correlation analysis indicated that MEG3 is positively correlated with GH and IGF-1 levels, and negatively correlated with tumor size $(\mathrm{r}=0.74, \mathrm{P}<0.0001 ; \mathrm{r}=0.72, \mathrm{P}<0.0001 ; \mathrm{r}=-0.75, \mathrm{P}<0.0001$, respectively; Fig. $4 \mathrm{~A}-\mathrm{C}$ ). The MEG3 with $2^{-\Delta \Delta \mathrm{Cq}}=479.75$ was set as a cut-off value, according to the Youden's index. The total 

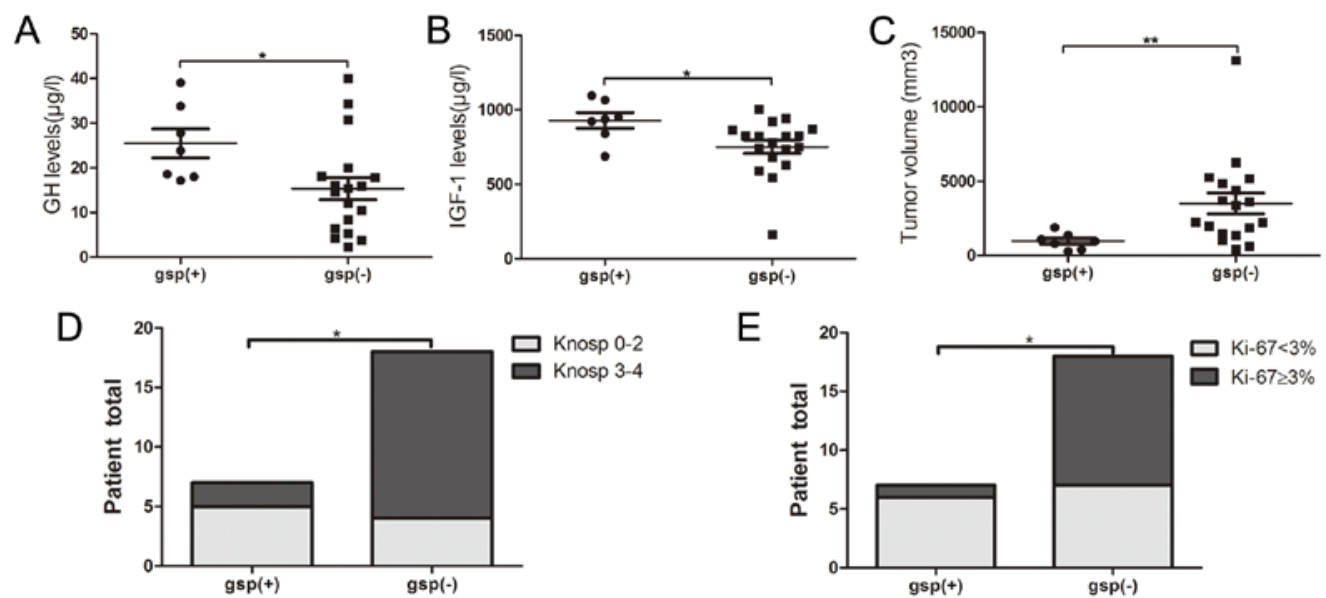

Figure 1. Comparison of (A) GH and (B) IGF-1 expression levels, (C) tumor volume, (D) Knosp grades and (E) Ki-67 labeling index in gsp-positive and gsp-negative groups. GH, growth hormone; IGF-1, insulin-like growth factor $1 .{ }^{*} \mathrm{P}<0.05$ and ${ }^{* *} \mathrm{P}<0.01$.
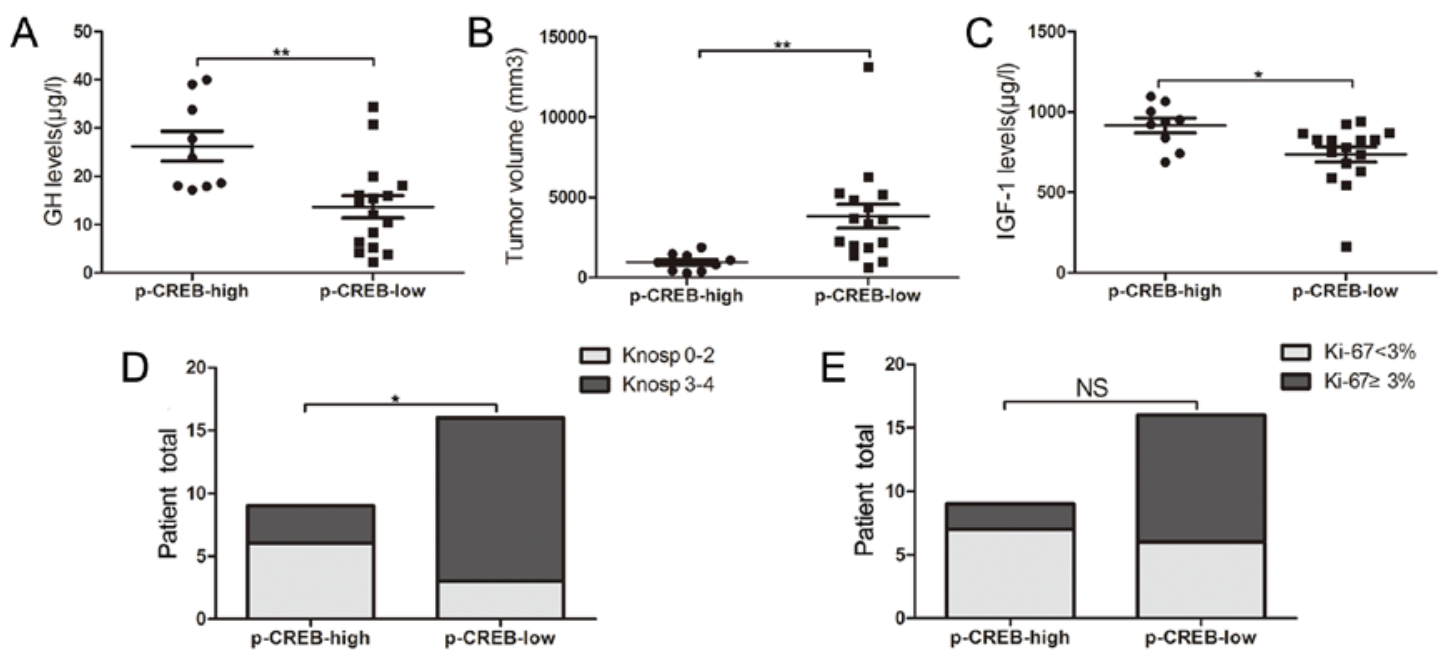

Figure 2. Comparison of (A) GH and (B) IGF-1 levels, (C) tumor volume, (D) Knosp grades and (E) Ki-67 labeling index between groups with low and high p-CREB expression. CREB, cyclic adenosine monophosphate-responsive element binding; p, phosphorylated; GH, growth hormone; IGF-1, insulin-like growth factor $1 .{ }^{*} \mathrm{P}<0.05$ and ${ }^{* *} \mathrm{P}<0.01$.

number of patients $(\mathrm{n}=25)$ with GH-secreting tumors were categorized into low- and high-expression groups. A significant difference was indicated in MEG3 expression between the two groups $(\mathrm{P}=0.0001$; Fig. 3B). The percentage of invasiveness (29 vs. $78 \%$; $\mathrm{P}=0.024)$ and $\mathrm{Ki}-67 \mathrm{Li}<3 \%$ (86 vs. $39 \%, \mathrm{P}=0.039$ ) were significantly reduced in the group with high MEG3 expression, compared with the group with low MEG3 expression (Fig. 4D and E).

Association among gsp oncogene, $p$-CREB and MEG3. MEG3 expression was significantly increased in the 7 gsp-positive tumors, compared with the 18 gsp-negative tumors $(1,083.2 \pm 922.9$ vs. $163.3 \pm 121.9$; $\mathrm{P}=0.039$; Fig. $5 \mathrm{~A}$ ). Patients with high $\mathrm{p}$-CREB expression indicated significantly increased expression levels of MEG3, compared with low p-CREB expression (902.2 \pm 878.7 vs. $150.1 \pm 113.4, \mathrm{P}=0.034$; Fig. $5 \mathrm{~B}$ ). A comparison between gsp-negative tumors and gsp-positive tumors additionally indicated a significantly increased level of p-CREB expression, according to immunohistochemical staining analysis $(882.3 \pm 88.1$ vs. $609.0 \pm 102.7 ; \mathrm{P}<0.0001$; Fig. 5 C).
Association between MEG3 and p53. No significant difference was indicated in p53 mutation between the low- and high-MEG3 expression groups, according to the immunohistochemical staining results (52 vs. $48 \%$; $\mathrm{P}=0.576$; Table I).

\section{Discussion}

A number of studies have been conducted to investigate the association between gsp oncogenes and clinical characteristics of patients with GH-secreting pituitary tumor $(8,11,12,17-19)$. The majority of the observations suggested that gsp-positive tumors indicated an increased secretory activity and reduced size, compared with gsp-negative tumors (9-11). Another study demonstrated that there were no significant differences of basal serum GH levels, IGF-I levels and tumor size in patients with or without a gsp oncogene (8). In the present study, the data indicated that a reduced tumor size, together with increased serum GH and IGF-1 levels, was indicative of the presence of a gsp-positive tumor. This observation is consistent with the previous studies that examined the association between gsp and the biochemical 

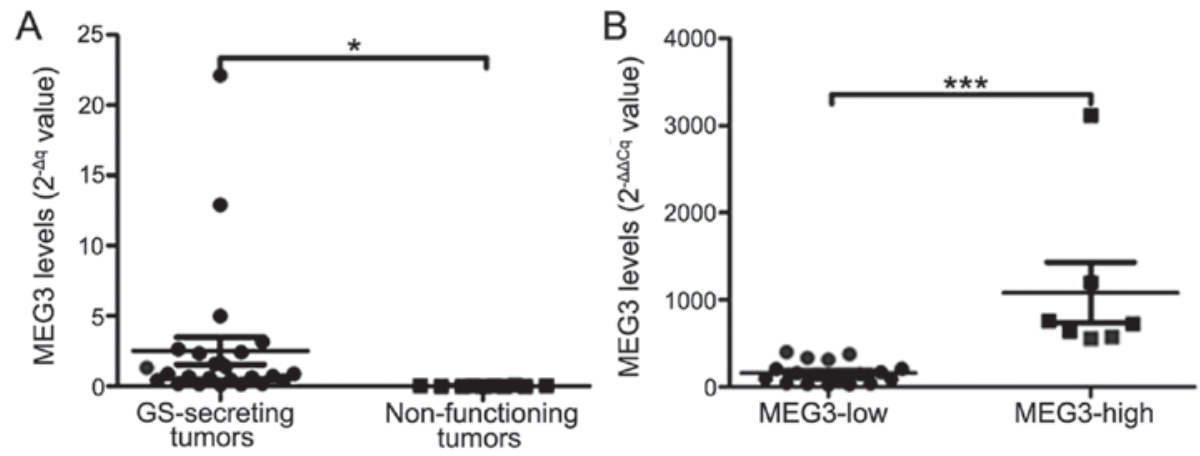

Figure 3. (A) The $2^{-\Delta C q}$ values of MEG3 in GH-secreting tumors and non-functioning tumors. (B) Difference in MEG3 expression of GH-secreting tumors between MEG3-low and MEG3-high groups. MEG3, maternally expressed gene 3; GH, growth hormone. ${ }^{*} \mathrm{P}<0.05$ and ${ }^{* * *} \mathrm{P}<0.0001$.

characteristics in patients with acromegaly (9-11). According to Knosp classification, the incidence of invasiveness was markedly reduced in the gsp-positive tumors, at $29 \%$, compared with the gsp-negative tumors, at $78 \%(\mathrm{P}=0.024)$. This conclusion is consistent with previous research (4). Although no difference was indicated in terms of $\mathrm{Ki}-67 \mathrm{Li}$ between the two groups in a previous study (8), the results of the present study indicated that the proliferation index was significantly reduced in gsp-positive tumors, compared with gsp-negative ones $(\mathrm{P}=0.039)$. The aforementioned observations demonstrated that gsp correlates with $\mathrm{GH}$ hypersecretion and reduces tumor size, as well as suppresses the rate of invasiveness and proliferation of $\mathrm{GH}$-secreting tumors.

Biochemical analyses explained that this was attributable to a defect in the Gs $\alpha$, which controlled adenylyl cyclase activity and increased intracellular cAMP levels $(20,21)$. The underlying mechanism of $\mathrm{GH}$ hypersecretion in $\mathrm{GH}$-secreting tumors may indicate that GH-releasing hormone uses cAMP as a second messenger to modulate GH secretion in somatotroph cells (22). For the effect on proliferation, cAMP may induce cell arrest or even inhibit mitogenic action of growth factors in a number of cell lines and conversely it may stimulate proliferation in other cell lines $(23,24)$. The mechanism that underlines high probability of gsp-positive tumors to bear small tumor volume remains unknown. The majority of the effects of cAMP were mediated by activating cAMP-dependent protein kinase A (PKA). CREB was phosphorylated by PKA and transactivates transcription of genes in response to hormonal stimulation of the cAMP pathway (25). Additionally, dimers of CREB bound to the enhancer-binding site, referred to as CRE, was indicated in the control regions of numerous genes, including c-jun, pit-1 and c-myc (26). Among the aforementioned genes, MEG3, as an imprinted gene, encoded a novel noncoding RNA that suppressed tumor cell proliferation (27), and was activated by the binding of CREB to CRE site as a downstream target gene of cAMP (28). A 'cross-talk' may occur between the cAMP signal pathway and MEG3 activation. Accordingly, it was speculated that the gsp oncogene may mediate MEG3 expression in suppressing proliferation and invasiveness, and promoting hormone hypersecretion of $\mathrm{GH}$-secreting pituitary tumors through the gsp/p-CREB/MEG3 signal pathway.

Previous study observations supported that the expression of MEG3 cDNA suppresses proliferation in a number of human tumor cell lines such as cervical carcinoma HeLa, breast adenocarcinoma MCF-7, and neuroglioma H4 (29). The study of Zhang et al (29) indicated that MEG3 represented a novel tumor suppressor gene, which may be involved in the pathogenesis of pituitary adenomas. In the present study, a strong expression of MEG3 RNA was observed in all $25 \mathrm{GH}$-secreting tumors, but almost no MEG3 RNA expression was detected in the 10 clinically nonfunctioning tumors, which is consistent with the previous research results (29). The most prominent observation of the present study is that MEG3 mRNA level is positively correlated with GH and IGF-1 levels, and negatively correlated with tumor volume. The aforementioned data indicate that MEG3 may serve an important role in a specific pathway controlling the $\mathrm{GH}$ secretion and cell proliferation. Additionally, the incidence of invasiveness was indicated to be notably reduced in tumors with high MEG3 expression, at $29 \%$, compared with tumors with low MEG3 expression, at $78 \%(\mathrm{P}=0.024)$. The Ki-67 index was significantly increased in the group with low MEG3 expression, compared with in the group with high MEG3 expression $(\mathrm{P}=0.039)$. The aforementioned results further confirm that a strong regulation effect of MEG3 overexpression on cell proliferation in GH-secreting pituitary tumors exists. Overall, this may indicate that MEG3 is physiologically involved in the control of $\mathrm{GH}$ production and proliferation.

A previous research has observed that p-CREB activates pituitary-specific transcription factor-1, which promotes the transcription of GH gene (30). The observations of the present study revealed that $\mathrm{p}-\mathrm{CREB}$ and MEG3 expression levels were significantly increased in gsp-positive tumors, compared with gsp-negative tumors $(\mathrm{P}<0.0001$ and $\mathrm{P}=0.039$, respectively). Additionally, MEG3 expression was frequently increased in the group with high p-CREB expression, compared with the group with low p-CREB expression $(\mathrm{P}=0.034)$. The aforementioned results indicated that the clinical characteristics of tumors with high p-CREB expression were similar to that of gsp-positive tumors and the high MEG3 expression group.

Additionally, the p53-dependent and p53-independent pathways have been reported to mediate tumor suppression induced by MEG3 (31). To investigate the role of p53 in suppressing MEG3 in GH-secreting pituitary tumors, p53 expression was analyzed in groups with low and high MEG3 expression levels. The data indicated no significant differences in p53 expression between the two groups. Therefore, in $\mathrm{GH}$-secreting pituitary tumors, MEG3 may serve a role in suppressing tumors through the p53-independent signaling pathways. 

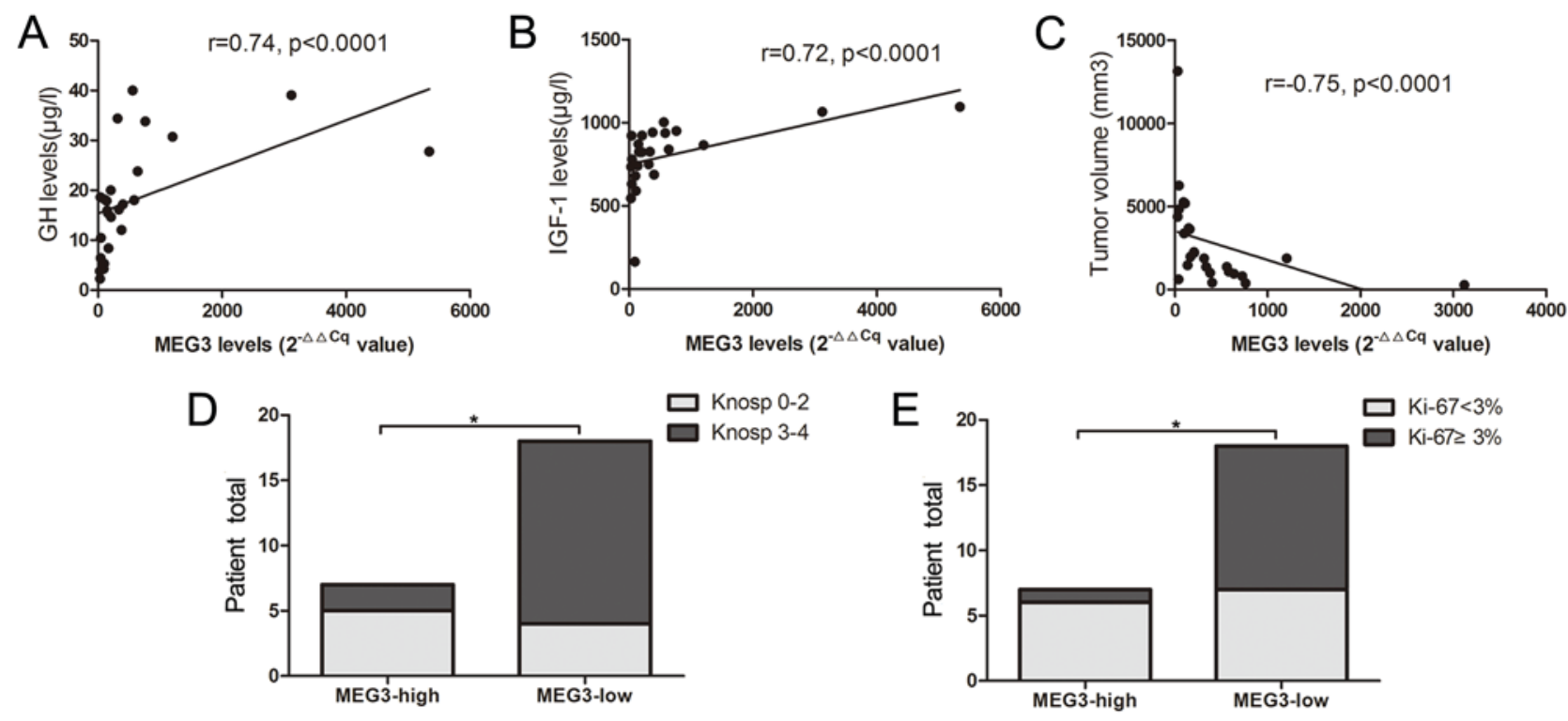

Figure 4. Correlation analysis among MEG3 and (A) GH, (B) IGF-1 levels, and (C) tumor volume. Comparison of (D) Knosp grades and (E) Ki-67 labeling index between groups with low and high MEG3 expression. MEG3, maternally expressed gene 3; GH, growth hormone; IGF-1, insulin-like growth factor 1; p-CREB, phospho-cyclic adenosine monophosphate-responsive element binding. ${ }^{*} \mathrm{P}<0.05$.

A
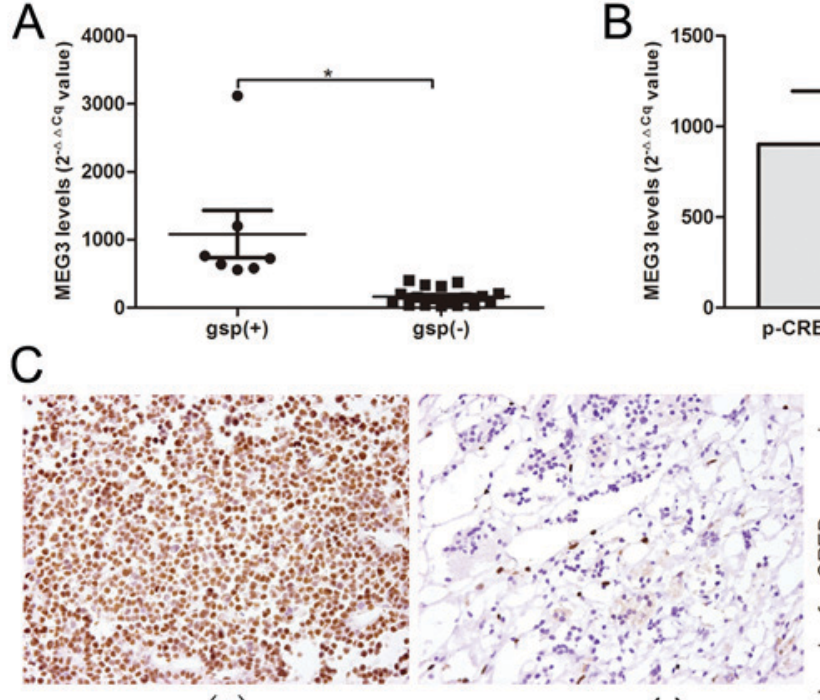

$\operatorname{gsp}(+)$
B

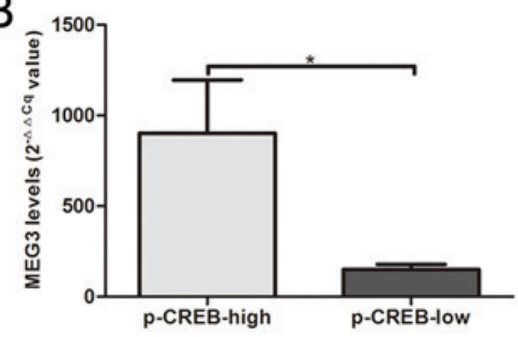

gsp(-)

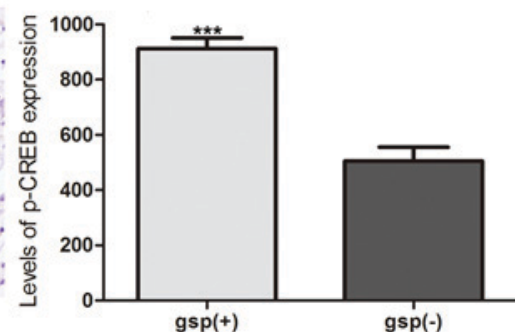

gsp(+) gsp(-)

Figure 5. (A) Difference in MEG3 expression between gsp-positive and gsp-negative groups. (B) The difference in MEG3 expression between groups with low and high p-CREB expression. (C) Immunohistochemical staining was performed to test p-CREB protein expression between gsp-positive and gsp-negative groups (magnification, $\mathrm{x} 400$ magnification). CREB, cyclic adenosine monophosphate-responsive element binding; p, phosphorylated; MEG3, maternally expressed gene 3. $\mathrm{P}<0.05$ and ${ }^{* * *} \mathrm{P}<0.0001$.

Further research is required to investigate whether gsp oncogene upregulates p-CREB expression levels to subsequently promote MEG3 expression. This information would further result in substantial differences in biochemical and clinical characteristics of GH-secreting tumors. There are, however, a number of limitations namely the gsp/p-CREB/MEG3 signal pathway has not been verified in GH3 cell. The role of MEG3 in regulating the $\mathrm{GH} 3$ cell proliferation and invasiveness has not been verified. MEG3 expression has reportedly caused apoptosis in numerous tumor cell lines, including tongue squamous cell carcinoma lines CAL-27 and SCC-15 (32), non-small cell lung cancer lines SPC-A1 and A549 (33), and glioma line
U251 (34). Previous data indicated that MEG3 suppresses tumor growth by causing cell cycle G1 arrest (35). Therefore, the underlying mechanism of tumor suppression through MEG3 in GH-secreting pituitary tumors remains to be investigated.

The correlation between MEG3 and gsp oncogene in gsp-positive and gsp-negative GH-secreting pituitary tumors, to the best of our knowledge, has not been previously reported. Collectively, the present study indicated that gsp oncogene promoted the overexpression of p-CREB, thereby enhancing MEG3 expression and eventually promoting hormone hypersecretion, as well as suppressing proliferation and invasiveness of GH-secreting pituitary tumors. 


\section{Acknowledgements}

Not applicable.

\section{Funding}

The present study received grants from the Applied Basic Research Programs of Science and Technology Commission Foundation of Jiangsu Province (grant no., BE2015684; Nanjing, China), and National Natural Science Foundation of China (grant no., 30801178; Beijing, China).

\section{Availability of data and materials}

All data generated or analyzed during the present study are included in this published article.

\section{Authors' contributions}

CT, CZ and CM designed the experiments. CT and CZ analyzed and interpreted the patient data. CM supervised the project. CT, CZ, JY, ZC, GW and JZ performed PCR, RT-qPCR and immunohistochemistry. CT, CZ and CM wrote the manuscript.

\section{Ethics approval and consent to participate}

Approval for the study was obtained from the Ethical Committee of Nanjing Jinling Hospital. Informed consent was obtained from all patients.

\section{Patient consent for publication}

Informed consent for publication was obtained from all patients.

\section{Competing interests}

The authors declare that they have no competing interest.

\section{References}

1. Freda PU, Chung WK, Matsuoka N, Walsh JE, Kanibir MN Kleinman G, Wang Y, Bruce JN and Post KD: Analysis of GNAS mutations in 60 growth hormone secreting pituitary tumors: Correlation with clinical and pathological characteristics and surgical outcome based on highly sensitive GH and IGF-I criteria for remission. Pituitary 10: 275-282, 2007.

2. Yasufuku-Takano J, Takano K, Morita K, Takakura K, Teramoto A and Fujita T: Does the prevalence of gsp mutations in GH-secreting pituitary adenomas differ geographically or racially? Prevalence of gsp mutations in Japanese patients revisited. Clin Endocrinol (Oxf) 64: 91-96, 2006.

3. Park C, Yang I, Woo J, Kim S, Kim J, Kim Y, Sohn S, Kim E, Lee M, Park H, Jung J and Park S: Somatostatin (SRIF) receptor subtype 2 and 5 gene expression in growth hormone-secreting pituitary adenomas: The relationship with endogenous srif activity and response to octreotide. Endocr J 51: 227-236, 2004.

4. Buchfelder M, Fahlbusch R, Merz T, Symowski H and Adams EF: Clinical correlates in acromegalic patients with pituitary tumors expressing GSP oncogenes. Pituitary 1: 181-185, 1999.

5. Ballare E, Mantovani S, Lania A, Di Blasio AM, Vallar L and Spada A: Activating mutations of the Gs alpha gene are associated with low levels of Gs alpha protein in growth hormone-secreting tumors. J Clin Endocrinol Metab 83: 4386-4390, 1998.
6. Yang I, Park S, Ryu M, Woo J, Kim S, Kim J, Kim Y and Choi Y: Characteristics of gsp-positive growth hormone-secreting pituitary tumors in Korean acromegalic patients. Eur J Endocrinol 134: 720-726, 1996

7. Hosoi E, Yokogoshi Y, Hosoi E, Horie H, Sano T, Yamada S and Saito S: Analysis of the Gs alpha gene in growth hormone-secreting pituitary adenomas by the polymerase chain reaction-direct sequencing method using paraffin-embedded tissues. Acta Endocrinol (Copenh) 129: 301-306, 1993.

8. Adams EF, Brockmeier S, Friedmann E, Roth M, Buchfelder M and Fahlbusch R: Clinical and biochemical characteristics of acromegalic patients harboring gsp-positive and gsp-negative pituitary tumors. Neurosurgery 33: 198-203, 1993.

9. Spada A, Arosio M, Bochicchio D, Bazzoni N, Vallar L, Bassetti M and Faglia G: Clinical, biochemical, and morphological correlates in patients bearing growth hormone-secreting pituitary tumors with or without constitutively active adenylyl cyclase. J Clin Endocrinol Metab 71: 1421-1426, 1990.

10. Spada A, Arosio M, Bassetti M, Vallar L, Clementi E and Bazzoni N: Mutations in the alpha subunit of the stimulatory regulatory protein of adenylyl cyclase (Gs) in human GH-secreting pituitary adenomas. Biochemical, clinical, and morphological aspects. Pathol Res Pract 187: 567-570, 1991.

11. Landis CA, Harsh G, Lyons J, Davis RL, McCormick F and Bourne HR: Clinical characteristics of acromegalic patients whose pituitary tumors contain mutant Gs protein. J Clin Endocrinol Metab 71: 1416-1420, 1990.

12. Goto Y, Kinoshita M, Oshino S, Arita H, Kitamura T, Otsuki M, Shimomura I, Yoshimine $\mathrm{T}$ and Saitoh Y: Gsp mutation in acromegaly and its influence on TRH-induced paradoxical GH response. Clin Endocrinol (Oxf) 80: 714-719, 2014.

13. Fusco A, Zatelli MC, Bianchi A, Cimino V, Tilaro L, Veltri F, Angelini F, Lauriola L, Vellone V, Doglietto F, et al: Prognostic significance of the Ki-67 labeling index in growth hormone-secreting pituitary adenomas. J Clin Endocrinol Metab 93: 2746-2750, 2008.

14. Thapar K, Scheithauer BW, Kovacs K, Pernicone PJ and Laws ER Jr: p53 expression in pituitary adenomas and carcinomas: Correlation with invasiveness and tumor growth fractions. Neurosurgery 38: 765-771, 1996.

15. Livak KJ and Schmittgen TD: Analysis of relative gene expression data using real-time quantitative PCR and the 2(-Delta Delta C(T)) method. Methods 25: 402-408, 2001.

16. Ruopp MD, Perkins NJ, Whitcomb BW and Schisterman EF: Youden Index and optimal cut-point estimated from observations affected by a lower limit of detection. Biom J 50: 419-430, 2008.

17. Kim HJ, Kim MS, Park YJ, Kim SW, Park DJ, Park KS, Kim SY, Cho BY, Lee HK, Jung HW, et al: Prevalence of Gs alpha mutations in Korean patients with pituitary adenomas. J Endocrinol 168: 221-226, 2001.

18. Metzler M, Luedecke DK, Saeger W, Grueters A, Haberl H, Kiess W, Repp R, Rascher W and Doetsch J: Low prevalence of Gs alpha mutations in śomatotroph adenomas of children and adolescents. Cancer Genet Cytogenet 166: 146-151, 2006.

19. Efstathiadou ZA, Bargiota A, Chrisoulidou A, Kanakis G, Papanastasiou L, Theodoropoulou A, Tigas SK, Vassiliadi DA, Alevizaki $\mathrm{M}$ and Tsagarakis S: Impact of gsp mutations in somatotroph pituitary adenomas on growth hormone response to somatostatin analogs: A meta-analysis. Pituitary 18: 861-867, 2015.

20. Clementi E, Malgaretti N, Meldolesi J and Taramelli R: A new constitutively activating mutation of the Gs protein alpha subunit-gsp oncogene is found in human pituitary tumours. Oncogene 5: 1059-1061, 1990.

21. Landis CA, Masters SB, Spada A, Pace AM, Bourne HR and Vallar L: GTPase inhibiting mutations activate the alpha chain of Gs and stimulate adenylyl cyclase in human pituitary tumours. Nature 340: 692-696, 1989.

22. Billestrup N,Swanson LW and Vale W: Growth hormone-releasing factor stimulates proliferation of somatotrophs in vitro. Proc Natl Acad Sci USA 83: 6854-6857, 1986.

23. Mantovani G, Bondioni S, Ferrero S, Gamba B, Ferrante E, Peverelli E,Corbetta S,Locatelli M,Rampini P,Beck-Peccoz P, et al: Effect of cyclic adenosine 3',5'-monophosphate/protein kinase a pathway on markers of cell proliferation in nonfunctioning pituitary adenomas. J Clin Endocrinol Metab 90: 6721-6724, 2005.

24. Pertuit M, Barlier A, Enjalbert A and Gérard C: Signalling pathway alterations in pituitary adenomas: Involvement of Gsalpha, cAMP and mitogen-activated protein kinases. J Neuroendocrinol 21: 869-877, 2009. 
25. Yamamoto KK, Gonzalez GA, Menzel P, Rivier J and Montminy MR: Characterization of a bipartite activator domain in transcription factor CREB. Cell 60: 611-617, 1990.

26. Meyer TE, Waeber G, Lin J, Beckmann W and Habener JF: The promoter of the gene encoding $3^{\prime}, 5^{\prime}$-cyclic adenosine monophosphate (cAMP) response element binding protein contains cAMP response elements: Evidence for positive autoregulation of gene transcription. Endocrinology 132: 770-780, 1993.

27. Zhang X, Rice K, Wang Y, Chen W, Zhong Y, Nakayama Y, Zhou Y and Klibanski A: Maternally expressed gene 3 (MEG3) noncoding ribonucleic acid: Isoform structure, expression, and functions. Endocrinology 151: 939-947, 2010.

28. Zhao J, Zhang X, Zhou Y, Ansell PJ and Klibanski A: Cyclic AMP stimulates MEG3 gene expression in cells through a cAMP-response element (CRE) in the MEG3 proximal promoter region. Int J Biochem Cell Biol 38: 1808-1820, 2006.

29. Zhang X, Zhou Y, Mehta KR, Danila DC, Scolavino S, Johnson SR and Klibanski A: A pituitary-derived MEG3 isoform functions as a growth suppressor in tumor cells. J Clin Endocrinol Metab 88: 5119-5126, 2003.

30. Frutos MG, Cacicedo L, Méndez CF, Vicent D, González M and Sánchez-Franco F: Pituitary alterations involved in the decline of growth hormone gene expression in the pituitary of aging rats. J Gerontol A Biol Sci Med Sci 62: 585-597, 2007.

31. Zhou Y, Zhong Y, Wang Y, Zhang X, Batista DL, Gejman R, Ansell PJ, Zhao J, Weng C and Klibanski A: Activation of p53 by MEG3 non-coding RNA. J Biol Chem 282: 24731-24742, 2007.
32. Jia LF, Wei SB, Gan YH, Guo Y, Gong K, Mitchelson K, Cheng J and Yu GY: Expression, regulation and roles of miR-26a and MEG3 in tongue squamous cell carcinoma. Int J Cancer 135: 2282-2293, 2014.

33. Lu KH, Li W, Liu XH, Sun M, Zhang ML, Wu WQ, Xie WP and Hou YY: Long non-coding RNA MEG3 inhibits NSCLC cells proliferation and induces apoptosis by affecting p53 expression. BMC Cancer 13: 461, 2013.

34. Wang P, Ren Z and Sun P: Overexpression of the long non-coding RNA MEG3 impairs in vitro glioma cell proliferation. J Cell Biochem 113: 1868-1874, 2012.

35. Chunharojrith P, Nakayama Y, Jiang X, Kery RE, Ma J, De La Hoz Ulloa CS, Zhang X, Zhou Y and Klibanski A: Tumor suppression by MEG3 lncRNA in a human pituitary tumor derived cell line. Mol Cell Endocrinol 416: 27-35, 2015. 